\title{
Botulinum Toxin Therapy versus Anterior Belly of Digastric Transfer in the Management of Marginal Mandibular Branch of the Facial Nerve Palsy: A Patient Satisfaction Survey
}

\author{
Daniel P Butler, Jo I Leckenby, Ben H Miranda, Adriaan O Grobbelaar \\ Department of Plastic and Reconstructive Surgery, The Royal Free Hospital, London, UK
}

Background Botulinum toxin (BT) chemodenervation and anterior belly of digastric muscle (ABD) transfer are both treatment options in the management of an isolated marginal mandibular branch of the facial nerve (MMB) palsy. We compare the patient satisfaction following either $\mathrm{BT}$ injections or $\mathrm{ABD}$ transfer in the management of their isolated MMB palsy. Methods Patients in the ABD-arm of the study were identified retrospectively from September 2007 to July 2014. The patients in the BT-arm of the study were identified prospectively from those attending the clinic. Both groups of patients completed a validated patient satisfaction survey. Statistical analysis was performed and a P-value $<0.05$ was considered statistically significant.

Results Seven patients were in the ABD-arm and 11 patients in the BT-arm of the study. The patient satisfaction in both groups was high with $45 \%$ of ABD-arm patients and $40 \%$ of BTarm patients rating their overall outcome as 'better' or 'much better', which was significantly more than the proportion rating their outcome as 'worse' or 'much worse' $(\mathrm{P}<0.001)$, although there was a significant trend towards those in the ABD-arm being more likely to be dissatisfied with their outcome $(P=0.01)$.

Conclusions BT therapy is a good first-line intervention in the management of isolated MMB palsy. We have, however, shown that the overall satisfaction in both groups is high. Therefore, in patients who would prefer a more permanent solution to manage their facial asymmetry, $A B D$ transfer remains a satisfactory treatment option with a good level of patient satisfaction.

Keywords Facial paralysis / Botulinum toxins / Facial asymmetry
Correspondence: Daniel P Butler Department of Plastic and Reconstructive Surgery, The Royal Free Hospital, Pond Street, London NW3 20G, UK

Tel: +44-7759-473296

Fax: +44-2078-302195

E-mail: danielbutler@nhs.net

No potential conflict of interest relevant to this article was reported.

\section{INTRODUCTION}

An isolated palsy of the marginal mandibular branch of the facial nerve (MMB) results in loss of the lower lip depressor muscle function. As a result, the lower lip on the affected side is elevat- ed, flattened and inwardly rotated when compared to the healthy, contralateral side [1].

The treatment of isolated MMB palsy can be split into two main groups: those that aim to restore movement on the paralysed side and those that aim to weaken the movement on the 
contralateral lower lip. To reanimate the affected side multiple options exist: transfer of the anterior belly of digastric muscle $(\mathrm{ABD})$ to the lower lip [2]; re-innervation of the lower lip depressors with mini-hypoglossal nerve transfer [3]; and free microneurovascular transfer of the extensor digitorum brevis have all been described [4]. Techniques to weaken movement from the lower lip on the other side include myotomy or myomectomy of the contralateral lower lip depressors [2] and botulinum toxin type A (BT) injections [5].

BT blocks presynaptic acetylcholine release at the neuromuscular junction resulting in reversible muscle paralysis. Chemodenervation is a well-recognised treatment option in the management of patients with long-standing facial paralysis [6-8] and, furthermore, its role in the management of patients with an isolated MMB palsy has also been described [5,9].

After a period of satisfactory denervation, frequently patients elect for a more permanent solution. The most commonly used approach in our unit is to perform an ipsilateral $\mathrm{ABD}$ transfer to the lower lip. The ABD is supplied by the mandibular branch of the trigeminal nerve and, therefore, remains functional in an isolated facial paralysis. The transfer of the ABD was first described by Edgerton [10] and subsequently modified by Conley and Baker [2] in 1982. The operative outcomes of ABD transfer in the management of isolated $\mathrm{MMB}$ palsy have previously been reported $[5,11]$.

What is, however, unknown is the patient satisfaction with these two different approaches. It is becoming increasingly important, particularly in healthcare systems where there is progressive rationing of resources, is to identify the patient-perceived benefits of any treatment provided. Our study, therefore, compares the patient satisfaction following either BT injections or $\mathrm{ABD}$ transfer in the management of their isolated MMB palsy.

\section{METHODS}

Patients in the ABD-arm of the study were identified through a retrospective review of the departmental electronic patient system from September 2007 and July 2014. All patients that underwent $\mathrm{ABD}$ transfer in the management of $\mathrm{MMB}$ palsy were included. All operations were performed by a single surgeon. The ABD was approached via a curvilinear submental incision and divided with its tendinous attachment to the hyoid bone. A separate linear incision was made at the vermillion border and a subcutaneous tunnel created to pass the $\mathrm{ABD}$ tendon from its mandibular insertion to the confluence of depressor labii inferioris and orbicularis oris (Fig. 1). The tendon was secured using a 4-0 Vicryl suture. Pre- and post-treatment photographs are shown in Fig. 2. The patients' medical records were reviewed to identify patient demographics, facial palsy aetiology and any previous or concomitant surgery. Patients were contacted via telephone to complete the patient satisfaction survey (Table 1).

The patients in the BT-arm of the study were identified prospectively from those attending the clinic. Eligible patients were those undergoing contralateral chemo-denervation of the lower lip depressor muscles in the management of their MMB palsy. Patients were excluded if they had undergone previous surgery on the ipsilateral or contralateral lower lip. Allergan Botox (onabotulinumtoxin A) was the form of the BT used in the study. A 100 unit vial was reconstituted with four millilitres of normal saline, which allowed the administration of 2.5 units per 0.1 millilitre of reconstituted toxin. The dosing protocol within our unit involves administering 15 units of Botox to the contralateral lower lip depressors. This dose is distributed vertically along the length of the depressors starting $1 \mathrm{~cm}$ below the vermillion border to avoid excessive paralysis of the orbicularis oris. Pre- and

Fig. 1. Operative technique of ABD trasnfer

$(A, B)$ Diagrammatic and $(C)$ intraoperative demonstration of the anterior-belly of digastric muscle (ABD) transfer.

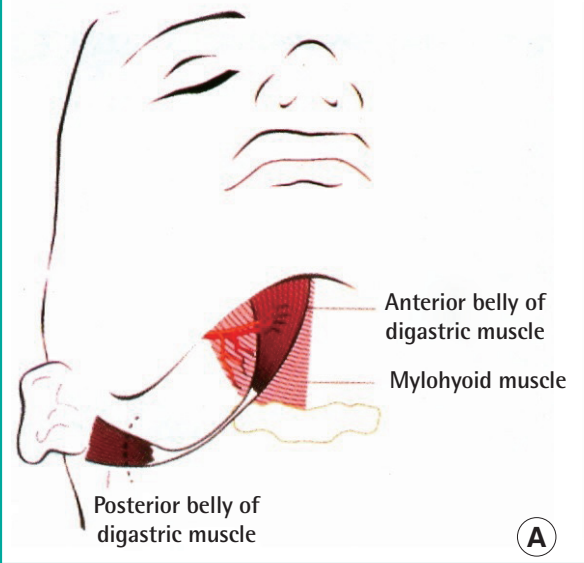

(A)

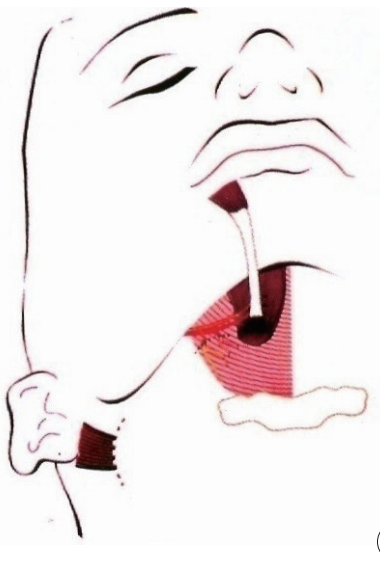

(B)

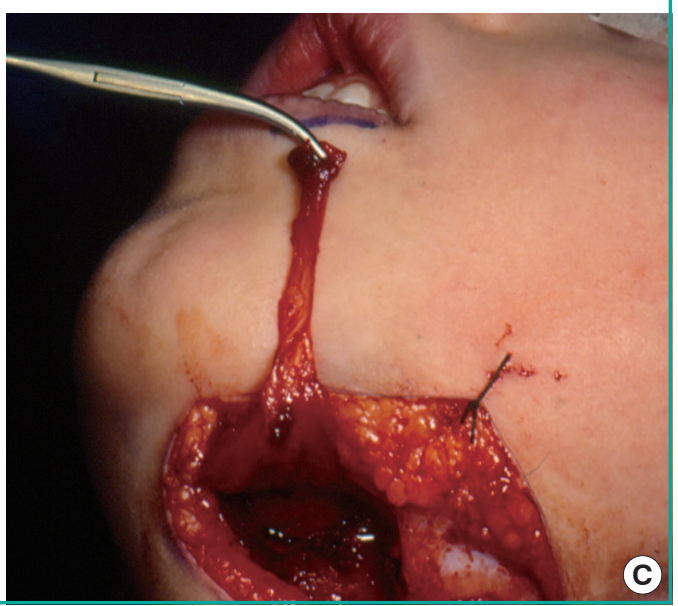


post-treatment photographs are shown in Fig. 3. The response to treatment is the evaluated at the subsequent clinic appointment, which occurs three months after treatment. There is not a system in place to review patients in the initial weeks after treatment due to the large distances patients travel to the centre and the logistical and financial limitations of the hospital resources.
As a result, any alteration to the dose and location of BT delivered must occur at the patient's three-month follow-up. In those patients that had only undergone one previous course of BT therapy, they were asked to complete the patient satisfaction survey based upon this previous course. In those patients that had received two or more previous courses of BT therapy, they

\section{Fig. 2. Anterior belly of digastric muscle transfer}

(A) Preoperatively, (B) postoperatively when smiling. Archive photo and patient not included in current study.
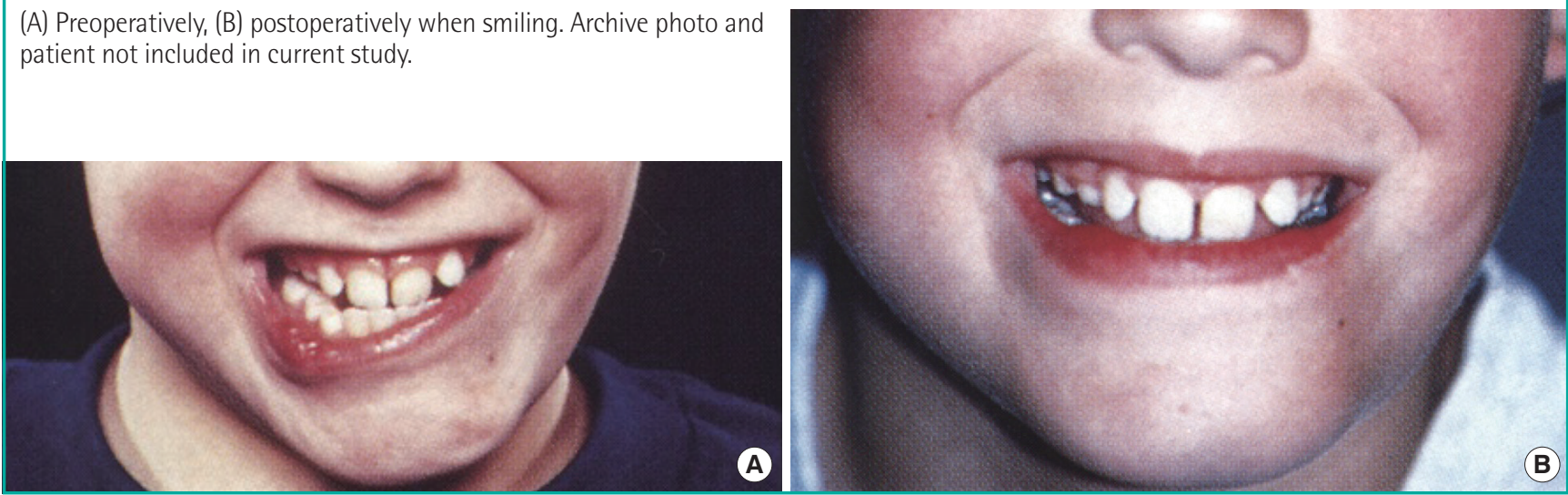

\section{Fig. 3. Botulinum toxin contralateral chemodenervation}

(A) Pre-treatment, (B) post-treatment when smiling. Archive photo and patient not included in current study.
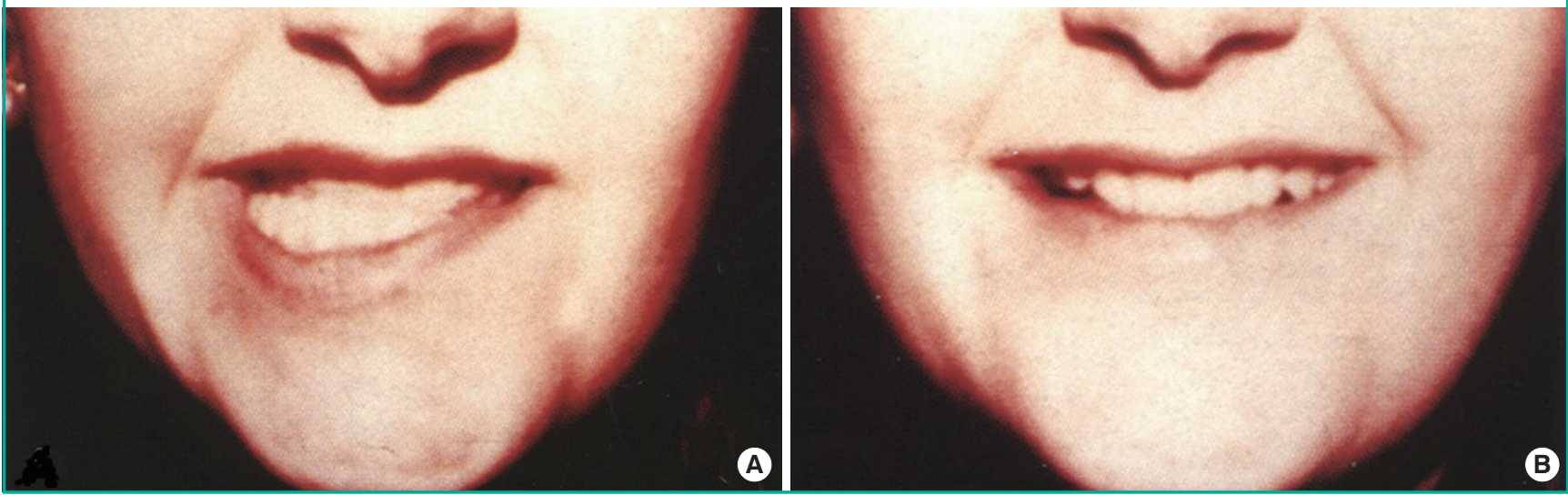

Table 1. An example questionnaire demonstrating the outcome domains recorded and the Likert scale used to quantify patient satisfaction

\begin{tabular}{|c|c|c|c|c|c|}
\hline \multirow{2}{*}{ Domain } & \multicolumn{5}{|c|}{ Outcome (please tick one box) } \\
\hline & Much worse & Worse & Unchanged & Better & Much better \\
\hline \multicolumn{6}{|l|}{ Change in appearance overall } \\
\hline \multicolumn{6}{|l|}{ Change in appearance at rest } \\
\hline \multicolumn{6}{|l|}{ Change in appearance smiling } \\
\hline \multicolumn{6}{|l|}{ Change in quality of life } \\
\hline \multicolumn{6}{|l|}{ Change in eye closure } \\
\hline \multicolumn{6}{|l|}{ Change in eye watering } \\
\hline \multicolumn{6}{|l|}{ Change in vision } \\
\hline \multicolumn{6}{|l|}{ Change in speech } \\
\hline \multicolumn{6}{|l|}{ Change in drooling } \\
\hline Change in social interaction confidence & & & & & \\
\hline
\end{tabular}


were asked to complete the patient satisfaction survey based upon the previous course that had given them the best outcome. The questionnaire was based upon a validated survey used to evaluate the patient satisfaction following BT injections in the management of aberrant facial nerve regeneration [12]. This was chosen over other well recognised, validated assessment tools designed to evaluate the satisfaction of the patients with facial palsy $[13,14]$, as it was considered to be more concise. It was, therefore, hoped that patient compliance in completing the questionnaire would be enhanced.

For single population proportion analysis a chi-square goodness of fit test was performed using IBM SPSS statistics software with $\mathrm{P}<0.05$ considered a significant result. When comparing the $\mathrm{ABD}$ and $\mathrm{BT}$ groups a statistical comparison between the number of patients that had rated their outcome as 'much better' or 'better' and those that had rated their outcome as 'much worse' or 'worse' was performed using Fisher's exact test with a two-tailed P-value $<0.05$ considered significant. Those that rated their outcome as 'unchanged' were excluded from the analysis. This was due to the large number of 'unchanged' outcomes reported when totalling the overall outcome. The reason for this was due to the design of the patient satisfaction questionnaire [12]. As with all validated facial palsy patient questionnaires, a number of questions relate specifically to ocular symptoms. As would be expected amongst a population of patients with an isolated MMB palsy, they did not suffer with any ocular symptoms and, therefore, rated their ocular symptoms as unchanged post-treatment. Although exclusion of the ocular questions from the chosen questionnaire would reduce this problem, we felt this would invalidate the questionnaire. It was, therefore, felt more appropriate to remove the 'unchanged' group from comparison analysis so that any trends in patient outcome could still be identified despite the relatively small sample size. Comparison was performed across all outcome domains as well as the overall patient reported outcome, calculated as the sum total of the number of patients that had selected each outcome across each of the domains.

\section{RESULTS}

A total of 13 patients were eligible for inclusion in the $A B D$-arm of the study amongst whom seven were contactable to ascertain patient satisfaction. Follow-up ranged from 6 months to 5 years (average, 19 months). A total of 11 patients were eligible for inclusion in the BT-arm of the study. The demographics of study population are shown in Table 2.

\section{Table 2. Patient demographics}

\begin{tabular}{|lcc|}
\hline Variable & $\begin{array}{c}\text { Botulinum } \\
\text { toxin-arm }\end{array}$ & $\begin{array}{c}\text { Anterior belly of } \\
\text { digastric-arm }\end{array}$ \\
\hline Age (yr) & $31(17-67)$ & $27(9-55)$ \\
Sex (female:male) & $9: 2$ & $6: 1$ \\
Aetiology & & \\
$\quad$ Congenital & 8 & 4 \\
Bell's palsy & 1 & 1 \\
Other infective & 1 & - \\
$\quad$ Tumour & 1 & - \\
$\quad$ latrogenic & - & 2 \\
Previous surgery & & \\
$\quad$ Free functional muscle transfer for smile & 2 & 2 \\
\hline Values are presented as average (range) or number. & \\
\hline
\end{tabular}

Table 3. Patient satisfaction for both treatment types according to each domain and the overall satisfaction as the sum of each domain

\begin{tabular}{|c|c|c|c|c|c|c|c|c|c|c|c|}
\hline Variable & $\begin{array}{l}\text { Change in } \\
\text { appearance } \\
\text { overall } \\
\text { ( } \% \text { in } \\
\text { brackets) }\end{array}$ & $\begin{array}{l}\text { Change in } \\
\text { appearance } \\
\text { at rest } \\
(\%)\end{array}$ & $\begin{array}{l}\text { Change in } \\
\text { appearance } \\
\text { smiling } \\
(\%)\end{array}$ & $\begin{array}{l}\text { Change } \\
\text { in quality } \\
\text { of life } \\
(\%)\end{array}$ & $\begin{array}{l}\text { Change } \\
\text { in eye } \\
\text { closure } \\
(\%)\end{array}$ & $\begin{array}{c}\text { Change } \\
\text { in eye } \\
\text { watering } \\
(\%)\end{array}$ & $\begin{array}{c}\text { Change } \\
\text { in vision } \\
(\%)\end{array}$ & $\begin{array}{c}\text { Change } \\
\text { in speech } \\
(\%)\end{array}$ & $\begin{array}{c}\text { Change } \\
\text { in } \\
\text { drooling } \\
(\%)\end{array}$ & $\begin{array}{c}\text { Social } \\
\text { interaction } \\
\text { confidence } \\
(\%)\end{array}$ & $\begin{array}{c}\text { Overall } \\
\text { satisfaction } \\
(\%)\end{array}$ \\
\hline \multicolumn{12}{|c|}{ Anterior belly of digastric transfer-arm } \\
\hline Much worse & 0 & 0 & 0 & 0 & 0 & 0 & 0 & 0 & 0 & $1(14)$ & $1(1)$ \\
\hline Worse & $1(14)$ & $1(14)$ & $1(14)$ & $1(14)$ & 0 & 0 & 0 & $1(14)$ & $3(43)$ & $1(14)$ & $9(13)$ \\
\hline Unchanged & 0 & $1(14)$ & 0 & $1(14)$ & $5(72)$ & $6(86)$ & $7(100)$ & $5(72)$ & $3(43)$ & $1(14)$ & $29(41)$ \\
\hline Better & $4(57)$ & $4(58)$ & $5(72)$ & $3(43)$ & $2(28)$ & $1(14)$ & 0 & $1(14)$ & $1(14)$ & $3(44)$ & $24(35)$ \\
\hline Much better & $2(29)$ & $1(14)$ & $1(14)$ & $2(29)$ & 0 & 0 & 0 & 0 & 0 & $1(14)$ & $7(10)$ \\
\hline \multicolumn{12}{|c|}{ Botulinum toxin-arm } \\
\hline Much worse & 0 & 0 & 0 & 0 & 0 & 0 & 0 & 0 & 0 & 0 & 0 \\
\hline Worse & 0 & 0 & 0 & 0 & 0 & 0 & 0 & $1(9)$ & $1(9)$ & 0 & $2(2)$ \\
\hline Unchanged & $1(9)$ & $6(55)$ & $1(10)$ & 2 (18) & $11(100)$ & $11(100)$ & $11(100)$ & $8(73)$ & $10(91)$ & $3(27)$ & $64(58)$ \\
\hline Better & $6(55)$ & $5(45)$ & $5(45)$ & $3(27)$ & 0 & 0 & 0 & $2(18)$ & 0 & $5(46)$ & $26(24)$ \\
\hline Much better & $4(36)$ & 0 & $5(45)$ & $6(55)$ & 0 & 0 & 0 & 0 & 0 & $3(27)$ & $18(16)$ \\
\hline
\end{tabular}


The patient satisfaction across each individual domain and the overall total for the two groups is shown in Table 3. There was a statistically significant difference within both treatment groups when analysing overall satisfaction towards patients' rating their outcome as 'better' or 'much better' (chi-square goodness of fit, $\mathrm{P}<0.001)$. When comparing the proportion of patients whose overall satisfaction was 'better' or 'much better' to the number of patients whose satisfaction was 'worse' or 'much worse' between the two treatment groups there was a significant trend towards those in the $\mathrm{ABD}$-arm being more likely to be dissatisfied with their outcome $(\mathrm{P}=0.01)$.

\section{DISCUSSION}

Paralysis of the MMB has both aesthetic and functional implications for the patient. Multiple treatment modalities exist to manage this condition and in our study we have compared the patient satisfaction following either contralateral BT chemo-denervation or ipsilateral ABD transfer. Our study has shown that there is a trend towards both groups being satisfied with the outcome of treatment. In fact, there was a greater proportion of patients in the $\mathrm{ABD}$-arm that were satisfied with their outcome than in the BT-arm when considering all outcomes (45\% vs. $40 \%$ ). It is, however, important to note that when comparing the proportion of patients that rated their outcome as 'worse' or 'much worse' to those that rated their outcome as 'better' or 'much better' there is a significantly increased risk of a patient being dissatisfied with their outcome following ABD transfer rather than $\mathrm{BT}$ therapy.

$\mathrm{ABD}$ transfer has been shown to produce good cosmetic results when compared to other surgical techniques for the management of $\mathrm{MMB}$ palsy [5]. The procedure takes approximately one-hour to perform, offers the potential for a permanent change in the appearance of the patient and creates minimal donor-site morbidity apart from the resulting scar in the submandibular triangle when harvesting the flap. Furthermore, the aim of the muscle transfer is to correct the position of the lower lip and vermillion border inversion. This may improve the speech and drooling problems that affect some patients. Interestingly, however, our patient satisfaction survey has shown that three of the seven patients rated their drooling as being worse following the procedure.

In the BT-arm, only one of the eleven patients surveyed rated their drooling as worse following treatment. This may be due to the differing aims of the two treatments with BT therapy aiming to denervate, and therefore elevate, the contralateral side, whereas $\mathrm{ABD}$ transfer has the intention of everting and lowering the paralysed side. If the tension on the $\mathrm{ABD}$ transfer is too great, the risk of drooling will increase. Our study has, however, not shown a statistically significant difference in the patient reported satisfaction specific to speech and drooling between the two treatment arms ( $\mathrm{P}>0.999$ for speech and drooling). This may, however, be due to the limited patient numbers in each group.

The significant difference observed in the overall patient satisfaction between those patients treated with BT and those managed with $\mathrm{ABD}$ transfer is, therefore, most likely down to a combination in the change in the patient's appearance and the impact that ABD transfer has on speech and drooling. Other studies that have asked independent observers to grade the aesthetic appearance of the lower lip at rest and when smiling and crying have found good cosmetic outcomes with BT therapy $[5,9]$.

Although the patient satisfaction with BT therapy is high, the treatment is limited by its temporary nature. While some have shown ongoing improved facial appearance up to six months post-BT treatment [6], patients in our unit are invited back for ongoing treatment every three months. The reversible nature of BT therapy has the benefit that any unwanted effects will be corrected within a number of months. In the setting of permanent facial paralysis, however, the patient will need to attend for therapy at regular intervals, lifelong, for ongoing benefit. The need for regular treatment may lead to the self-selection of patients who are more satisfied with the outcome following their BT treatment and this may, therefore, impact upon the findings from our study.

Based upon the study data, BT therapy is an appropriate firstline intervention in the management of isolated MMB palsy. We have, however, shown that the overall satisfaction in both groups is high. Therefore, in patients who would prefer a more permanent solution to manage their facial asymmetry, $\mathrm{ABD}$ transfer remains a satisfactory treatment option with a good level of patient satisfaction. Patients should, however, be warned of the potential for being dissatisfied with their outcome if managed with an $A B D$ transfer.

\section{REFERENCES}

1. Moffat DA, Ramsden RT. The deformity produced by a palsy of the marginal mandibular branch of the facial nerve. J Laryngol Otol 1977;91:401-6.

2. Conley J, Baker DC. Paralysis of the mandibular branch of the facial nerve. Plast Reconstr Surg 1982;70:569-77.

3. Terzis JK, Tzafetta K. Outcomes of mini-hypoglossal nerve transfer and direct muscle neurotisation for restoration of lower lip function in facial palsy. Plast Reconstr Surg 2009; 124:1891-904.

4. Mayou BJ, Watson S, Harrison DH, et al. Free microvascular 
and microneural transfer of the extensor digitorum brevis muscle for the treatment of unilateral facial palsy. Br J Plast Surg 1981;34:362-7.

5. Tulley P, Webb A, Chana JS, et al. Paralysis of the marginal mandibular branch of the facial nerve: treatment options. $\mathrm{Br}$ J Plast Surg 2000;53:378-85.

6. Salles AN, Toledo PN, Ferreira MC. Botulinum toxin injection in long-standing facial paralysis patients: improvement of facial symmetry observed up to 6 months. Aesth Plast Surg 2009;33:582-90.

7. Maio M, Bento RF. Botulinum toxin in facial palsy: an effective treatment for contralateral hyperkinesis. Plast Reconstr Surg 2007;120:917-27.

8. Mehta RP, Hadlock TA. Botulinum toxin and quality of life in patients with facial paralysis. Arch Facial Plast Surg 2008; 10:84-7.

9. Chen CK, Tang YB. Myectomy and botulinum toxin for paralysis of the marginal mandibular branch of the facial nerve: a series of 76 cases. Plast Reconstr Surg 2007;120:1859-64.

10. Edgerton MT. Surgical correction of facial paralysis: a plea for better reconstruction. Ann Surg 1967;165:985-98.

11. Tan ST. Anterior belly of digastric muscle transfer: a useful technique in head and neck surgery. Head Neck 2002;24: 947-54.

12. Borodic G, Bartley M, Slattery W, et al. Botulinum toxin for aberrant facial nerve regeneration: double-blind, placebo controlled trial using subjective endpoints. Plast Reconstr Surg 2005;116:36-43.

13. Kahn JB, Gliklich RE, Boyev KP, et al. Validation of a patientgraded instrument for facial nerve paralysis: the $\mathrm{FaCE}$ scale. Laryngoscope 2001;111:387-98.

14. VanSwearingen JM, Brach JS. The facial disability index: reliability and validity of a disability assessment instrument for disorders of the facial neuromuscular system. Phys Ther 1996;76:1288-98. 